\title{
Catalytic activity of copper-bis(oxazoline) grafted on mesoporous silica in enantioselective cyclopropanation
}

\author{
Fatma Fakhfakh, ${ }^{*}$ Leila Baraket, ${ }^{\ddagger}$ Abdelhamid Ghorbel, ${ }^{\ddagger}$ José M. Fraile ${ }^{\dagger}{ }^{\text {José A. Mayoral }}{ }^{\dagger}$
}

† Université de Tunis El Manar, Faculté des Sciences de Tunis, Département de Chimie, Laboratoire de Chimie des Matériaux et Catalyse, 2092, Tunis, Tunisie.

† Instituto de Síntesis Química y Catálisis Homogénea (ISQCH), Facultad de Ciencias, C.S.I.C.-Universidad de Zaragoza, Pedro Cerbuna 12, E-50009 Zaragoza, Spain.

Corresponding author:

E-mail address: fatma.fakhfakh@gmail.com

Tel: $+21650223208 ;$ fax : +21671871929

\begin{abstract}
Chiral phenyl substituted bis(oxazoline) (PhBox) was covalently immobilized through carbamate linkers onto mesoporous silica materials. These supports were previously prepared by a sol-gel method and they exhibit different textural properties. The presence and the integrity of the bis(oxazoline) ligand was checked by ${ }^{13} \mathrm{C}-\mathrm{CP}-\mathrm{MAS}-\mathrm{NMR}$. These chiral mesoporous materials were complexed with copper (II) triflate. In spite of the different textural properties of these supports, the copper loading, determined by ICP-AES, was nearly the same (0.041$0.044 \mathrm{mmol} \mathrm{Cu} / \mathrm{g}$ of solid). The supported $\mathrm{Cu}$ (II) complexes were tested as catalysts in the enantioselective cyclopropanation of styrene with ethyl diazoacetate. Enantioselectivities are consistently lower than those obtained in homogeneous phase. Different analyses point to a difficulty in the formation of the expected chelate, due to the presence of a coordinating functional group in the linker, as responsible for the loss in enantioselectivity. The textural properties of the materials do significantly affect the behavior upon recovery.
\end{abstract}

Keywords Mesoporous materials, Immobilized catalysts, Bis(oxazoline), Cyclopropanation. 


\section{Introduction}

The development of new heterogeneous catalysts able to promote enantioselective organic reactions is a field of growing interest because of the important advantages of heterogeneous to homogenous catalysts, the main one being that the supported catalyst can be easily recovered and then reused [1,2]. The immobilization of chiral homogeneous catalysts on solid insoluble supports is the most common method to prepare chiral heterogeneous catalysts, and two general approaches can be used for this immobilization: the first one consists in covalently fixing the chiral ligand to the support $[3,4]$, whereas the second one uses some non-covalent interaction between the complex and the solid support [5]. The main advantage of the covalent immobilization is to avoid the leaching of the valuable chiral ligand. As solid support, organic polymers and different kinds of silica are commonly used for the covalent attachment. Silica supported catalysts show in principle stronger mechanical resistance and a structure which is independent from the solvent used. Moreover, the restriction in the attack trajectories to the chiral complex in mesoporous solids has been the origin of interesting confinement effects on selectivity $[6,7]$.

As chiral ligands, bis(oxazolines) are among the most versatile ones, since they form complexes with different cations and can promote a large variety of enantioselective organic reactions [8]. Their metal complexes have been immobilized on mesoporous materials through non-covalent interactions, such as hydrogen-bonding [9] and electrostatic interactions [10,11,12]. The covalent immobilization of bis(oxazoline) ligands on silica support could be achieved in situ by sol-gel method or by grafting on a pre-formed support. The synthesis by sol-gel process [13] presents the problem that the bis(oxazoline) ligands are sensitive to hydrolysis in aqueous acidic media, together with the possible occlusion of the ligand in non-accessible parts of the hybrid material. Regarding grafting on different silica supports, one key point is the choice of the spacer linking the bis(oxazoline) ligand and the support. A simple alkyl chain has been used, either anchoring an alkyl halide on the silica support and making it to react with a methylene bis(oxazoline) $[14,15,16,17,18]$ or alkylating first the ligand and then grafting the modified bis(oxazoline) $[19,20,21]$. In other cases the spacer has functional groups, such as thioether $[22,23]$, ether $[24,25]$, carbamate $[26,27,28]$ or even polyfunctional spacers prepared by click chemistry [29]. Some of those works deal with the covalent immobilization on amorphous silicas and in other examples ordered mesoporous materials are used as supports, namely 
MCM41 and MCM48 [14,23], SBA15 and HMS [17,18,25], mesocellular foam silicas [19,20,21,24], and hierarchically-ordered mesocellular mesoporous silica [29].

In this work the anchoring of phenyl substituted bis(oxazoline) ligand to mesoporous silica through a carbamate linker $\mathrm{CH}_{2}-\mathrm{O}-\mathrm{CONH}-\left(\mathrm{CH}_{2}\right)_{3}$ is reported, used until now only to immobilize the indane [26,27] and the tert-butyl [28] bis(oxazolines). The catalytic performance in the cyclopropanation between styrene and ethyl diazoacetate is compared with the analogous indane derivative [30].

\section{Experimental}

\section{Synthesis of mesoporous supports}

To a solution of tetraethoxysilane (TEOS, $9.1 \mathrm{~mL}, 40 \mathrm{mmol})$ in propanol $(20 \mathrm{~mL})$ at the required temperature was added either acetic or propionic acid $(4 \mathrm{mmol})$ and then water $(4.2 \mathrm{~mL})$. The final molar composition of the mixture was TEOS:propanol: $\mathrm{H}_{2} \mathrm{O}$ :acid $=1: 6.5: 6: 0.1$. The resulting solution was stirred at the same temperature until gelification, and then for an additional period of $24 \mathrm{~h}$. The resulting product was transferred into a Teflon-lined autoclave to be aged at $120^{\circ} \mathrm{C}$ for $24 \mathrm{~h}$, and finally it was dried at $120{ }^{\circ} \mathrm{C}$ for $24 \mathrm{~h}$ in an oven.

\section{Synthesis of the chiral ligand}

2,2'-Methylenebis[(4S)-4-phenyl-2-oxazoline] (PhBox) was synthesized by reacting $(S)$-2phenylglycinol (10 mmol, 1.37g) with diethyl malonimidate dihydrochloride (5 mmol, $1.15 \mathrm{~g}$ ) in dichloromethane $(100 \mathrm{~mL})$. After 15 hours of stirring at room temperature the resulting mixture was extracted 3 times with $100 \mathrm{~mL}$ of $\mathrm{H}_{2} \mathrm{O}$. The organic fraction was dried with $\mathrm{MgSO}_{4}$ and the solvent was removed under reduced pressure to obtain a yellow liquid [31].

${ }^{1} \mathrm{H}$ NMR (300 MHz, $\left.\mathrm{CDCl}_{3}, \delta / \mathrm{ppm}\right):$ 7.26-7.20 (m, 10H), $5.22(\mathrm{~m}, 2 \mathrm{H}), 4.67(\mathrm{t}, 2 \mathrm{H}), 4.11$ (t, 2H), 3.51 (s, 2H); ${ }^{13} \mathrm{C} \mathrm{NMR}\left(75 \mathrm{MHz}, \mathrm{CDCl}_{3}, \delta / \mathrm{ppm}\right): 162.0,141.6,128.6,127.5,126.6,75.2$, $69.7,28.3$.

After that, the ligand was functionalized in the methylene bridge by hydroxymethylation. PhBox (1 mmol, $0.308 \mathrm{~g}$ ) was added to a solution of paraformaldehyde (2.5 mmol, $78 \mathrm{mg}$ ) in $\mathrm{CH}_{2} \mathrm{Cl}_{2}(4 \mathrm{~mL})$. After that dioxane $(1 \mathrm{~mL})$ and water $(0.2 \mathrm{~mL})$ were added. Finally, a solution of triethylamine $(2.96 \mathrm{mmol}, 0.4 \mathrm{~mL})$ in tetrahydrofuran $(3 \mathrm{~mL})$ was added dropwise for 3 hours 
and the mixture was kept under stirring at room temperature. After 3 days, the solvent was evaporated under reduced pressure, $\mathrm{CH}_{2} \mathrm{Cl}_{2}(20 \mathrm{~mL})$ was added and the solution was washed with water $(3 \times 20 \mathrm{~mL})$. The organic phase was dried with $\mathrm{MgSO}_{4}$ and the solvent was removed under reduced pressure.

${ }^{1} \mathrm{H}$ NMR (300MHz, $\left.\mathrm{CDCl}_{3}, \delta / \mathrm{ppm}\right):$ 7.32-7.24 (m, 10H), $5.21(\mathrm{~m}, 2 \mathrm{H}), 4.67(\mathrm{t}, 2 \mathrm{H}), 4.11(\mathrm{t}$, 2H), $3.74(\mathrm{~m}, 4 \mathrm{H}), 3.70$ (s, 2H); ${ }^{13} \mathrm{C} \mathrm{NMR}\left(75 \mathrm{MHz}, \mathrm{CDCl}_{3}, \delta / \mathrm{ppm}\right): 161.9,141.6,128.8,127.8$, 126.5, 75.0, 69.0, 67.0, 64.5.

The hydroxymethylated ligand was made react with 3-isocyanatopropyltriethoxysilane [26,27]. The hydroxymethylated ligand ( $1 \mathrm{mmol}, 0.364 \mathrm{~g})$ was added to a solution of dry triethylamine (3.3 mmol, $0.5 \mathrm{~mL})$ in dry toluene $(5 \mathrm{~mL})$ under inert atmosphere. The 3isocyanatopropyltriethoxysilane $(2.2 \mathrm{mmol}, 0.55 \mathrm{~mL})$ was added dropwise for $20 \mathrm{~min}$. The mixture was kept under stirring at room temperature for $48 \mathrm{~h}$. The solvent was evaporated under reduced pressure and the crude reaction was used for grafting without further purification.

${ }^{1} \mathrm{H}$ NMR (300MHz, $\left.\mathrm{CDCl}_{3}, \delta / \mathrm{ppm}\right): 7.98(\mathrm{~s}, 2 \mathrm{H}), 7.32-7.24(\mathrm{~m}, 10 \mathrm{H}), 5.23(\mathrm{~m}, 2 \mathrm{H}), 5.01$ (t, 4H), $4.67(\mathrm{t}, 2 \mathrm{H}), 4.11(\mathrm{t}, 2 \mathrm{H}), 3.78(\mathrm{~m}, 12 \mathrm{H}) ; 3.13(\mathrm{~m}, 4 \mathrm{H}), 1.56(\mathrm{~m}, 4 \mathrm{H}), 1.19(\mathrm{~m}, 18 \mathrm{H}), 0.60$ (m, 4H). ${ }^{13} \mathrm{C}$ NMR (75 MHz, $\left.\mathrm{CDCl}_{3}, \delta / \mathrm{ppm}\right): 162.2,158.3,142.0,128.5,127.4,126.4,75.2$, $70.1,58.1,42.6,36.2,31.1,23.4,18.0,7.3$.

\section{Immobilization of the ligand onto the supports}

The corresponding dried silica support $(500 \mathrm{mg})$ was added to a solution of functionalized PhBox $(150 \mathrm{mg}, 0.17 \mathrm{mmol})$ in anhydrous toluene $(5 \mathrm{~mL})$ and the resulting suspension was heated under reflux for $48 \mathrm{~h}$ under inert atmosphere. The solid was filtered, thoroughly washed with toluene and dichloromethane, and dried under vacuum. The copper complexes were prepared by addition of $\mathrm{Cu}(\mathrm{OTf})_{2}(35 \mathrm{mg}, 0.098 \mathrm{mmol})$ to a suspension of the bis(oxazoline)containing material $(570 \mathrm{mg})$ in anhydrous methanol $(2 \mathrm{~mL})$. After $15 \mathrm{~h}$ stirring, the solid was filtered, washed with methanol and dried under vacuum.

\section{Characterization}

Nitrogen physisorption experiments were performed at 77K on an ASAP 2000 apparatus. The surface area was calculated using the BET method [32]. The pore size distribution was obtained from the desorption branch of isotherms using the BJH method [33]. ${ }^{13} \mathrm{C}-\mathrm{CP}-\mathrm{MAS}-\mathrm{NMR}$ 
spectra were recorded at $100.62 \mathrm{MHz}$ on a Bruker Avance SB $400 \mathrm{MHz}$ spectrometer at room temperature and magic angle spinning at $4000 \mathrm{~Hz}$, with $5.2 \mu \mathrm{s}$ excitation pulse and $5 \mathrm{~s}$ recycle time. Copper analysis was carried out on a Perkin-Elmer Plasma Emission spectrometer.

\section{Cyclopropanation reaction}

The solid catalyst (160 mg) was added to a solution of styrene (156 mg, $1.5 \mathrm{mmol})$ and $n$-decane (50 mg, internal standard) in anhydrous dichloromethane $(2 \mathrm{~mL})$. A solution of ethyl diazoacetate $(171 \mathrm{mg}, 1.5 \mathrm{mmol})$ in anhydrous dichloromethane $(0.7 \mathrm{~mL})$ was slowly added (2 h) with a syringe pump. The reaction was monitored by GC [34]. After total conversion of diazoacetate, the catalyst was filtered off and washed with dichloromethane $(5 \mathrm{~mL})$, dried under vacuum and reused under the same conditions. The enantioselectivities were determined by gas chromatography with a Cyclodex- $\beta$ column. The oven temperature program is an isotherm at $125^{\circ} \mathrm{C}$. The retention times for the different cyclopropanes are $28.9 \mathrm{~min}$ for $(1 \mathrm{~S}, 2 \mathrm{R})$ cyclopropane, $29.8 \mathrm{~min}$ for $(1 \mathrm{R}, 2 \mathrm{~S})$-cyclopropane, $34.3 \mathrm{~min}$ for $(1 \mathrm{R}, 2 \mathrm{R})$-cyclopropane and $34.9 \min$ for (1S, 2R)-cyclopropane.

\section{Results and discussion}

\section{Synthesis and characterization of the chiral catalysts}

Mesoporous silica materials were prepared by sol-gel method in propanol with a small amount of a carboxylic acid as catalyst without using any template [35]. The textural properties were determined from the $\mathrm{N}_{2}$ adsorption-desorption isotherms, which are given in Fig. 1 together with the pore size distribution. The results are gathered in Table 1.

Silica materials prepared by sol-gel show type IV $\mathrm{N}_{2}$ isotherms with different hysteresis loop shape, indicating the formation of mesoporous materials with different pore shape. Besides, these silica materials do not present any microporosity (Table 1). When the synthesis is carried out in propanol at $35{ }^{\circ} \mathrm{C}$ with acetic acid as catalyst (material S-1), a surface area of $876 \mathrm{~m}^{2} / \mathrm{g}$ and a main pore diameter of $35 \AA$ were obtained. An increase in the synthesis temperature to $60^{\circ} \mathrm{C}$ (material S-2) produces an increase in the void volume of the solid, which favors the formation of larger pores (mean pore diameter $120 \AA$ ) and larger total pore volume $\left(1.12 \mathrm{~cm}^{3} / \mathrm{g}\right)$. When acetic acid is substituted by propionic acid (material S-3), the resulting solid exhibits 
large surface area $\left(479 \mathrm{~m}^{2} / \mathrm{g}\right)$ and the highest total pore volume $\left(1.76 \mathrm{~cm}^{3} / \mathrm{g}\right)$, with a very large mean pore diameter.

Table 1 Synthesis conditions and textural properties of silica materials ${ }^{\text {a }}$

\begin{tabular}{llccccc}
\hline Solid & Catalyst & $\mathrm{T}\left({ }^{\circ} \mathrm{C}\right)$ & $\mathrm{S}_{\text {BET }}\left(\mathrm{m}^{2} / \mathrm{g}\right)$ & $\mathrm{D}(\AA)$ & $\mathrm{V}_{\text {mic }}\left(\mathrm{cm}^{3} / \mathrm{g}\right)$ & $\mathrm{V}_{\mathrm{p}}\left(\mathrm{cm}^{3} / \mathrm{g}\right)$ \\
\hline $\mathrm{S}-1$ & $\mathrm{CH}_{3} \mathrm{COOH}$ & 35 & 876 & 35 & 0 & 0.77 \\
S-2 & $\mathrm{CH}_{3} \mathrm{COOH}$ & 60 & 609 & 120 & 0 & 1.12 \\
S-3 & $\mathrm{C}_{2} \mathrm{H}_{5} \mathrm{COOH}$ & 60 & 479 & 289 & 0 & 1.76
\end{tabular}

${ }^{\text {a }} \mathrm{S}_{\mathrm{BET}}=$ surface area $\left(\mathrm{m}^{2} / \mathrm{g}\right), \mathrm{D}(\AA)=$ maximum of the pore size distribution, $\mathrm{V}_{\text {mic }}=$ microporous volume calculated by t-plot method $\left(\mathrm{cm}^{3} / \mathrm{g}\right), \mathrm{V}_{\mathrm{p}}=$ total pore volume at $\mathrm{P} / \mathrm{P}_{0}=0.98$.
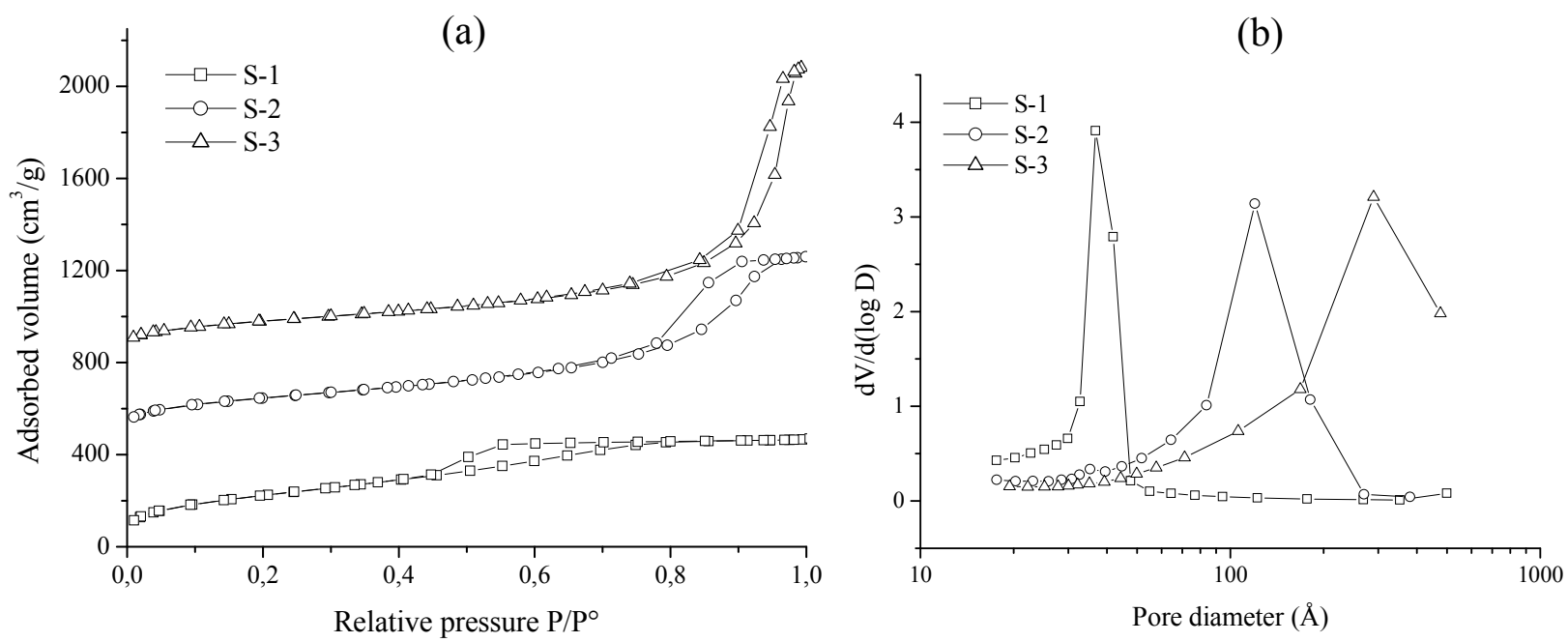

Fig 1 (a) $\mathrm{N}_{2}$ adsorption-desorption isotherms and (b) pore size distribution of silica materials S-1, S-2 and S-3.

PhBox was functionalized with triethoxysilane groups through carbamate linkers (Scheme 1). The hydroxymethylation with paraformaldehyde was the first step followed by the reaction with 3-isocyanatopropyltriethoxysilane according to a method described in the literature [26,27]. The resulting functionalized ligand was anchored onto the different silica supports (S-1, S-2 and S-3) in toluene under reflux to obtain the materials S-1-PhBox, S-2-PhBox and S-3-PhBox. These functionalized solids were characterized by ${ }^{13} \mathrm{C}-\mathrm{CP}-\mathrm{MAS}-\mathrm{NMR}$, in order to check the presence and the integrity of the chiral ligand. 


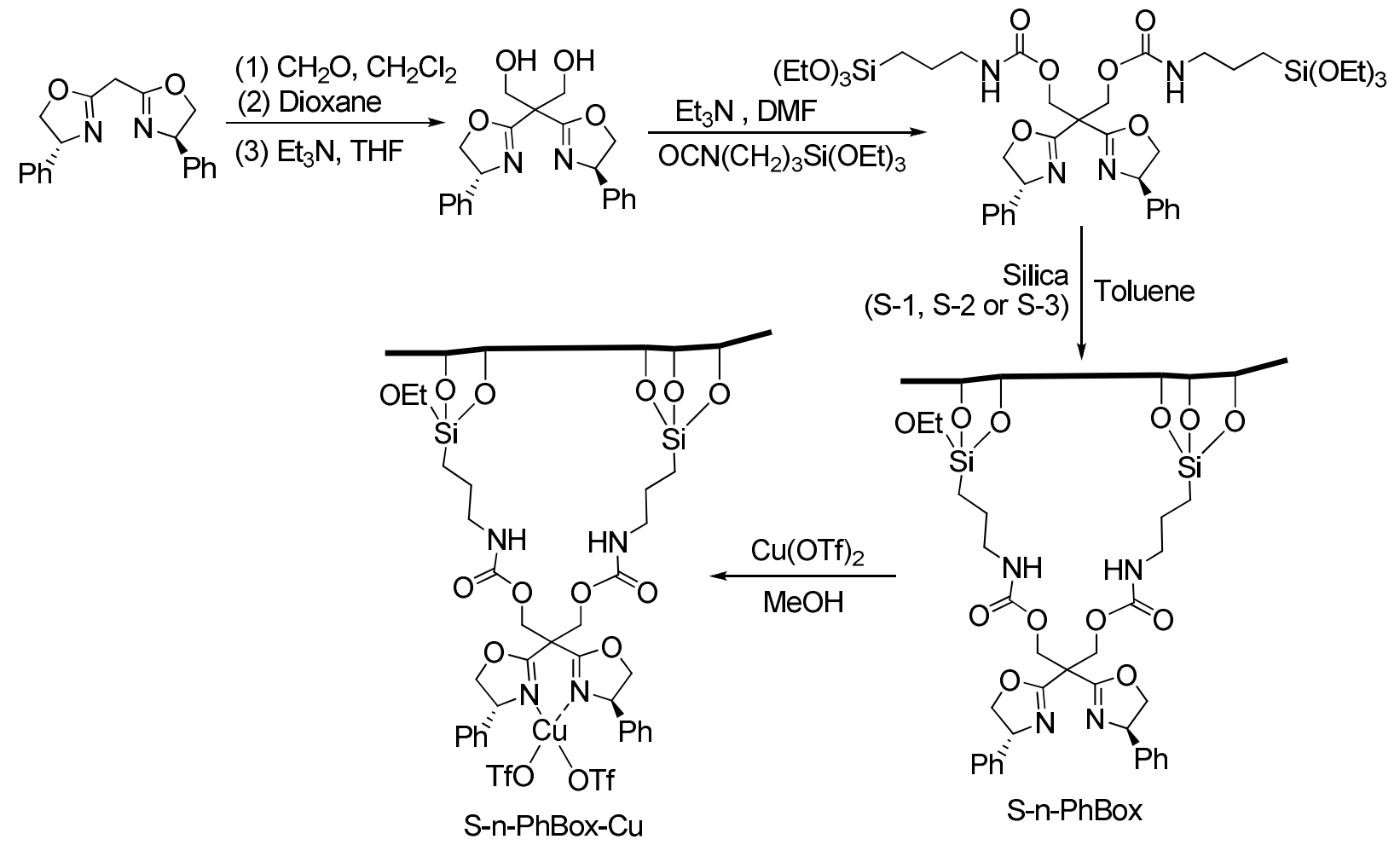

Scheme 1 Synthesis steps of the heterogeneous catalysts

The ${ }^{13} \mathrm{C}-\mathrm{CP}-\mathrm{MAS}-\mathrm{NMR}$ spectra of the chiral materials S-1-PhBox, S-2-PhBox and S-3-PhBox are shown in Fig.2. All the spectra are similar, revealing the presence of the most important signals of the bis(oxazoline) ligand and the carbamate linker. All the signals were assigned to the corresponding carbons as seen in the Fig.2. The presence of residual ethoxy groups indicates the incomplete condensation of the ethoxysilane with the surface silanols.

Finally, the materials containing the chiral ligand were complexed with $\mathrm{Cu}(\mathrm{OTf})_{2}$ in methanol (Scheme 1). These catalytic materials are labeled S-1-PhBox-Cu, S-2-PhBox-Cu and S-3$\mathrm{PhBox}-\mathrm{Cu}$. The copper loading and the textural properties of the final catalysts were determined and they are gathered in Table 2. As can be seen the immobilization of the chiral PhBox ligand and the subsequent copper complexation produces a drop in surface area and total pore volume of the mesoporous materials S-1 to S-3, but with only a slight effect on the mean pore diameter. Copper loading in all the mesoporous chiral materials is very similar, from 0.041 to 0.044 $\mathrm{mmol} / \mathrm{g}$, in spite of the very different surface area of the three supports. Thus the highest copper surface density, $0.13 \mu \mathrm{mol} / \mathrm{m}^{2}$, corresponds to the support with largest pores, probably due to an improved accessibility to the whole surface of the solid. 


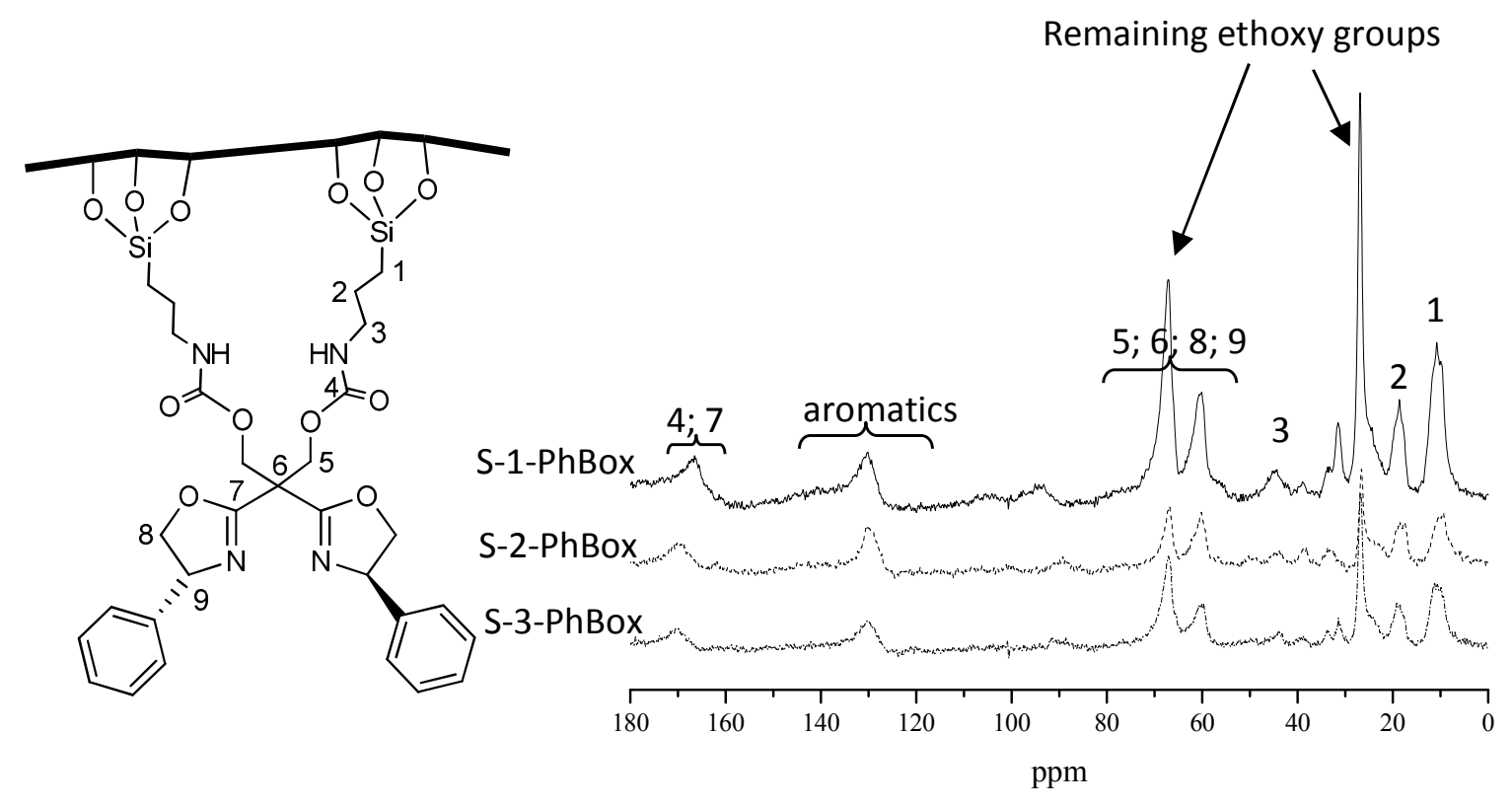

Fig. $2{ }^{13} \mathrm{C}-\mathrm{CP}-\mathrm{MAS}-\mathrm{NMR}$ spectra of the solids $\mathrm{S}-1-\mathrm{PhBox}, \mathrm{S}-2-\mathrm{PhBox}$ and $\mathrm{S}-3-\mathrm{PhBox}$

Table 2 Textural properties and copper content of the catalysts ${ }^{\text {a }}$

\begin{tabular}{lccccc}
\hline Catalyst & $\mathrm{S}_{\text {BET }}\left(\mathrm{m}^{2} / \mathrm{g}\right)$ & $\mathrm{D}(\AA)$ & $\mathrm{V}_{\mathrm{p}}\left(\mathrm{cm}^{3} / \mathrm{g}\right)$ & $\mathrm{Cu}(\mathrm{mmol} / \mathrm{g})$ & $\mathrm{Cu}\left(\mu \mathrm{mol} / \mathrm{m}^{2}\right)$ \\
\hline $\mathrm{S}-1-\mathrm{PhBox}-\mathrm{Cu}$ & 583 & 35 & 0.52 & 0.043 & 0.07 \\
$\mathrm{~S}-2-\mathrm{PhBox}-\mathrm{Cu}$ & 372 & 120 & 0.86 & 0.041 & 0.11 \\
$\mathrm{~S}-3-\mathrm{PhBox}-\mathrm{Cu}$ & 328 & 278 & 1.16 & 0.044 & 0.13
\end{tabular}

${ }^{\mathrm{a}} \mathrm{S}_{\mathrm{BET}}=$ surface area $\left(\mathrm{m}^{2} / \mathrm{g}\right), \mathrm{D}(\AA)=$ maximum of the pore size distribution, $\mathrm{V}_{\mathrm{p}}=$ total pore volume at $\mathrm{P} / \mathrm{P}_{0}=0.98$.

The ligand functionalization of the solid and the degree of ligand complexation with copper can be estimated from the elemental analysis. The results are collected in Table 3, together with those obtained in the grafting of the indane derived bis(oxazoline) on the same supports [30]. First of all the $\mathrm{C} / \mathrm{N}$ molar ratios, in the range of 7.5-7.8, are in good agreement with the theoretical value (7.25), also considering the presence of residual ethoxy groups, as shown in the NMR spectra (Fig 2). It is also worthy to note that the amount of PhBox grafted ligand, around $0.25 \mathrm{mmol} / \mathrm{g}$, is significantly higher than in the case of indBox (around $0.18 \mathrm{mmol} / \mathrm{g}$ ). This can be due to the higher flexibility of PhBox, in comparison with the polycyclic indBox, allowing an easier diffusion through the mesopores of the supports. On the contrary, the degree 
of complexation is rather low. The N/Cu molar ratio is around 23 in all the three solids, whereas the theoretical ratio for a total complexation is 4 . This result is also very different from those obtained with the indBox ligand. In that case the ligand complexation is not complete either, but the $\mathrm{N} / \mathrm{Cu}$ molar ratio is always lower, in the range of 8.6-13.3. It can be speculated that the easiness for diffusion of the more flexible PhBox ligand allows the grafting on sites that are later on inaccessible for $\mathrm{Cu}(\mathrm{OTf})_{2}$.

Table 3 Copper and elemental analysis of fresh and recovered catalysts ${ }^{\text {a }}$

\begin{tabular}{|c|c|c|c|c|c|c|}
\hline \multirow[t]{2}{*}{ Catalyst } & \multicolumn{3}{|c|}{ Fresh catalyst } & \multicolumn{3}{|c|}{ Recovered catalyst } \\
\hline & $\mathrm{Cu}$ & $\mathrm{N}$ & $\mathrm{C}$ & $\mathrm{Cu}$ & $\mathrm{N}$ & $\mathrm{C}$ \\
\hline $\mathrm{S}-1-\mathrm{PhBox}-\mathrm{Cu}$ & 0.043 & 0.96 & 7.49 & 0.034 & 1.04 & 9.20 \\
\hline $\mathrm{S}-2-\mathrm{PhBox}-\mathrm{Cu}$ & 0.041 & 1.01 & 7.59 & 0.024 & 0.97 & 9.64 \\
\hline $\mathrm{S}-3-\mathrm{PhBox}-\mathrm{Cu}$ & 0.044 & 0.98 & 7.57 & 0.043 & 1.02 & 8.83 \\
\hline S-1-indBox-Cu ${ }^{b}$ & 0.091 & 0.78 & 8.96 & 0.071 & 0.74 & 12.27 \\
\hline S-2-indBox-Cu ${ }^{b}$ & 0.057 & 0.76 & 7.08 & 0.031 & 0.81 & 9.05 \\
\hline S-3-indBox-Cub & 0.061 & 0.72 & 6.86 & 0.025 & 0.64 & 6.70 \\
\hline
\end{tabular}

${ }^{\mathrm{a}}$ Content in $\mathrm{mmol} / \mathrm{g} .{ }^{\mathrm{b}}$ Results from ref. [30] corresponding to the catalysts with indane bis(oxazoline) on the same supports.

\section{Results in the cyclopropanation reaction}

The immobilized copper (II) complexes were tested as catalysts in the benchmark cyclopropanation reaction between styrene and ethyl diazoacetate represented in Scheme 2. The catalytic results are gathered in Table 4, together with those obtained with the analogous indane derived bis(oxazoline) ligand (indBox) grafted on the same silica supports [30].

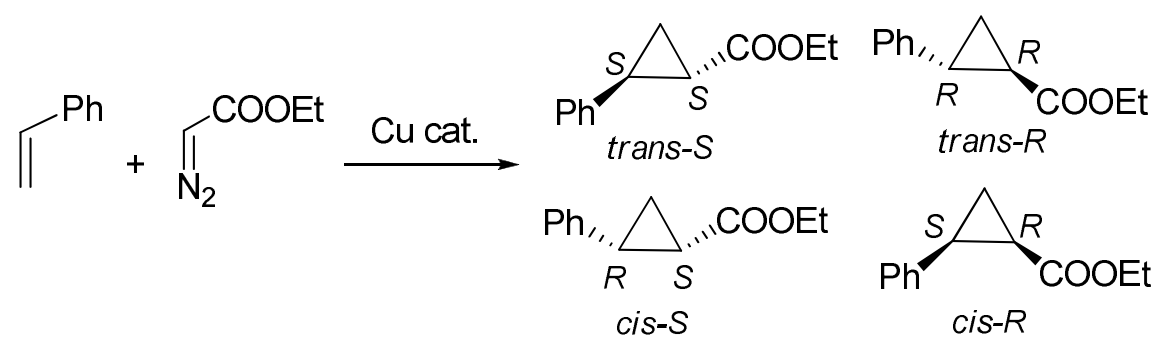

Scheme 2 Asymmetric cyclopropanation of styrene with ethyl diazoacetate 
Table 4 Results of the catalyzed cyclopropanation reactions ${ }^{\text {a }}$

\begin{tabular}{|c|c|c|c|c|c|}
\hline Catalyst & Run & Yield (\%) & trans/cis & $\%$ e.e. $c i s^{\mathrm{b}}$ & $\%$ e.e. $\operatorname{trans}^{\mathrm{b}}$ \\
\hline $\operatorname{PhBox}\left(\mathrm{Me}_{2}\right)-\mathrm{Cu}^{\mathrm{c}}$ & 1 & 33 & $68 / 32$ & 51 & 60 \\
\hline \multirow[t]{2}{*}{$\mathrm{Hyb}-\mathrm{PhBox}-\mathrm{Cu}^{\mathrm{d}}$} & 1 & 33 & $64 / 32$ & 53 & 45 \\
\hline & 2 & 30 & $59 / 41$ & 50 & 43 \\
\hline \multirow[t]{2}{*}{$\mathrm{S}-1-\mathrm{PhBox}-\mathrm{Cu}$} & 1 & 30 & $63 / 37$ & 22 & 27 \\
\hline & 2 & 34 & $63 / 37$ & 2 & 4 \\
\hline \multirow[t]{2}{*}{$\mathrm{S}-2-\mathrm{PhBox}-\mathrm{Cu}$} & 1 & 53 & $62 / 38$ & 11 & 22 \\
\hline & 2 & 45 & $63 / 37$ & 2 & 9 \\
\hline \multirow[t]{2}{*}{$\mathrm{S}-3-\mathrm{PhBox}-\mathrm{Cu}$} & 1 & 30 & $63 / 37$ & 24 & 30 \\
\hline & 2 & 12 & $62 / 38$ & 6 & 7 \\
\hline indBox $\left(\mathrm{Me}_{2}\right)-\mathrm{Cu}^{\mathrm{c}}$ & 1 & 52 & $60 / 40$ & 81 & 85 \\
\hline \multirow[t]{2}{*}{$\mathrm{S}$-1-indBox-Cu} & 1 & 45 & $56 / 44$ & 52 & 43 \\
\hline & 2 & 39 & $57 / 43$ & 46 & 35 \\
\hline \multirow[t]{2}{*}{ S-2-indBox-Cu } & 1 & 37 & $57 / 43$ & 52 & 42 \\
\hline & 2 & 20 & $58 / 42$ & 40 & 30 \\
\hline \multirow[t]{2}{*}{ S-3-indBox-Cu } & 1 & 33 & $56 / 44$ & 57 & 48 \\
\hline & 2 & 2 & $58 / 42$ & 37 & 29 \\
\hline
\end{tabular}

${ }^{\mathrm{a}}$ Reaction conditions: $\mathrm{Cu}=2 \mathrm{~mol} \%$, styrene $=1.5 \mathrm{mmol}$, dichloromethane $(2 \mathrm{~mL})$, slow addition (syringe pump, $2 \mathrm{~h}$ ) of ethyl diazoacetate (1.5 mmol in $0.7 \mathrm{~mL} \mathrm{CH}_{2} \mathrm{Cl}_{2}$ ), rt. Results determined by GC. ${ }^{\mathrm{b}}$ Major isomers: trans-S and $c i s-S .{ }^{\mathrm{c}}$ Results with the homogeneous complex from ref. [34]. ${ }^{\mathrm{d}}$ Results from ref. [¡Error! Marcador no definido.] corresponding to a hybrid material prepared by sol-gel method with $\mathrm{PhBox}$ functionalized with a propyl linker. ${ }^{\mathrm{e}}$ Results from ref. [30] corresponding to the catalysts with indane bis(oxazoline) on the same supports.

The homogeneous $\mathrm{PhBox}\left(\mathrm{Me}_{2}\right)-\mathrm{Cu}$ complex leads to moderate enantioselectivities for both cis (51\% e.e.) and trans (60\% e.e.) isomers, as well as moderate yield (due to the competitive side dimerization of the diazocompound) and the typical trans/cis selectivity, close to 70/30 [36]. In the case of the immobilized catalysts, the enantioselectivities are significantly lower, $11-24 \%$ e.e. for cis cyclopropanes and $22-30 \%$ e.e. for trans cyclopropanes, with the best results 
obtained with $\mathrm{S}-3-\mathrm{PhBox}-\mathrm{Cu}$, and very close results with $\mathrm{S}-1-\mathrm{PhBox}-\mathrm{Cu}$. With both catalysts the obtained yield is comparable to that of the homogeneous catalyst. On the contrary the lowest enantioselectivities correspond to $\mathrm{S}-2-\mathrm{PhBox}-\mathrm{Cu}$, the catalyst leading to the highest yield, even higher than the result in solution, which seems to indicate an important contribution of copper sites uncomplexed with the immobilized ligand.

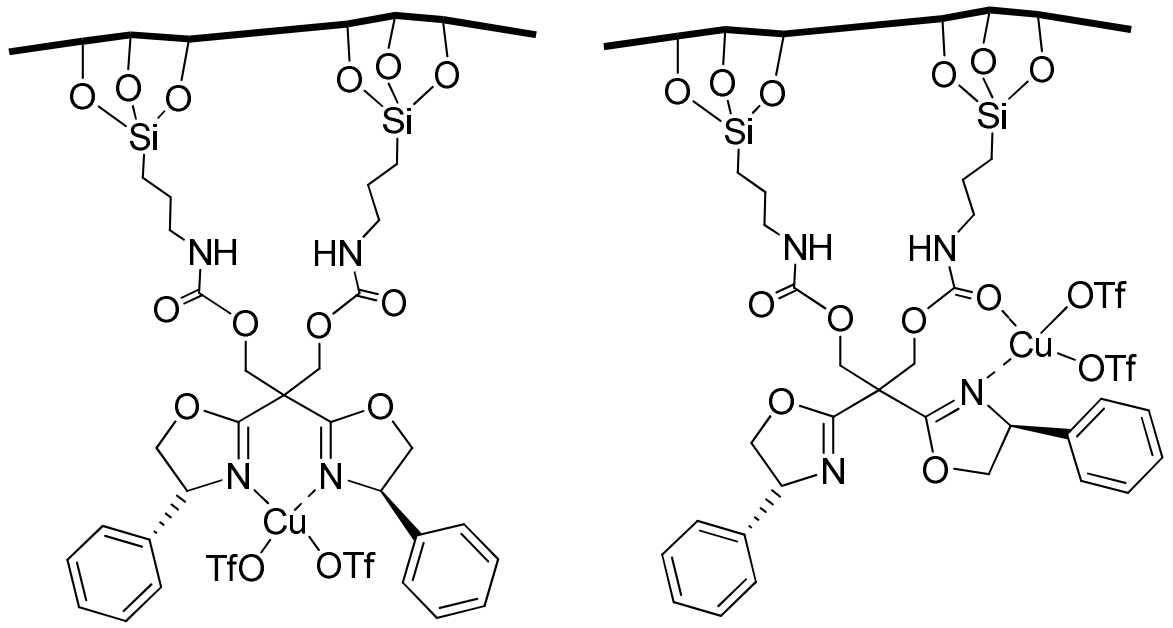

Fig. 3 Possible coordination modes for grafted PhBox: chelate mode (left) and mixed ligandlinker mode (right)

When these results are compared with those obtained with indBox (Table 4), it can be seen that the rigid ligand leads to better results in enantioselectivity, $52-57 \%$ e.e. for cis and $42-48 \%$ e.e. for trans cyclopropanes. However, a deeper inspection of the results requires the calculation of the difference in the energy of the diastereomeric transition states $\left(\Delta E_{a}\right)$, as this is the parameter that controls the enantioselectivity. From the relative abundances of both enantiomers it can be calculated that, in the case of $\mathrm{PhBox}$, the immobilization on $\mathrm{S} 1$ and $\mathrm{S} 3$ provokes a decrease in that difference $\left(\Delta \Delta E_{a}\right)$ of around $0.4 \mathrm{kcal} / \mathrm{mol}$ in the $c i s$ and $0.45-0.5 \mathrm{kcal} / \mathrm{mol}$ in the trans cyclopropanes. However, from the results with indBox, immobilization provokes in that case a $\Delta \Delta E_{a}$ of around $0.6 \mathrm{kcal} / \mathrm{mol}$ for $c i s$ and $0.9 \mathrm{kcal} / \mathrm{mol}$ for trans cyclopropanes, that is the effect of immobilization on the relative energy of the transition states is higher in the case of indBox. On the contrary, the results of PhBox grafting on different solids using a unfunctionalized propyl linker described in the literature $[13,14]$ show that the enantioselectivity was not significantly modified with respect to the result in solution, indicating an important role of the linker in this effect. The presence of a linker functionalized with coordinating groups, and the 
possible restrictions in the conformational freedom of the ligand inside the mesopores, may induce different coordination modes (Fig. 3), including one mixed ligand-linker one, whose enantioselectivity would be lower than the typical chelate mode $[37,38,39]$. Thus unfunctionalized propyl linker seems to be more suitable for grafting on silica supports. However, recently it has been described the grafting of PhBox with this linker on several solid supports [18], including mesoporous silicas, and in most cases the results [40] are similar to those reported here and in only one case enantioselectivities are close to those obtained in solution.

After recycling these chiral catalysts shows a drop in the enantioselectivities for both cis and trans cyclopropanes to values below $10 \%$ e.e., but the yields are similar in S-1-PhBox-Cu and $\mathrm{S}-2-\mathrm{PhBox}-\mathrm{Cu}$, whereas the reused $\mathrm{S}-3-\mathrm{PhBox}-\mathrm{Cu}$ is much less active for cyclopropanation. This effect had been also observed in the case of supported indBox [30], in spite of being the solid with the largest pores. The analysis of the recovered catalysts (Table 3) that $\mathrm{Cu}$ leaching is lower in the case of PhBox than in indBox, and even null in S-3-PhBox-Cu. This result demonstrates that leaching is not the main origin of the deactivation.

The $\mathrm{N}_{2}$ adsorption-desorption isotherms and the pore size distribution of the material S-2$\mathrm{PhBox}-\mathrm{Cu}$ before use and after the second run are given in Fig. 4. After use, the $\mathrm{N}_{2}$ isotherm is still of type IV but the hysteresis loop has changed from H1 to H3. This suggests the modification in the shape of the pores, from pores have regular dimensions not interconnected (H1 type), to slit-shaped pores (H3 type) [41,42]. Also the pore size is reduced from $120 \AA$ to $110 \AA$, with the appearance of smaller pores of about $33 \AA$. Besides, the surface area dropped from $372 \mathrm{~m}^{2} / \mathrm{g}$ to $281 \mathrm{~m}^{2} / \mathrm{g}$, and the same trend was observed for the total pore volume, which was reduced from $0.86 \mathrm{~cm}^{3} / \mathrm{g}$ to $0.79 \mathrm{~cm}^{3} / \mathrm{g}$, although it does not present any microporosity. All these results demonstrate some blockage of the pores by organic groups, in agreement with the increase in carbon content (up to $2 \mathrm{mmol} / \mathrm{g}$, Table 3 ). This must be due to the presence of products or by-products (diethyl fumarate and maleate from dimerization of diazoacetate, as well as oligomers), mainly on the copper sites, which has been proposed as the main deactivation mechanism in other supported box-Cu complexes [43]. 

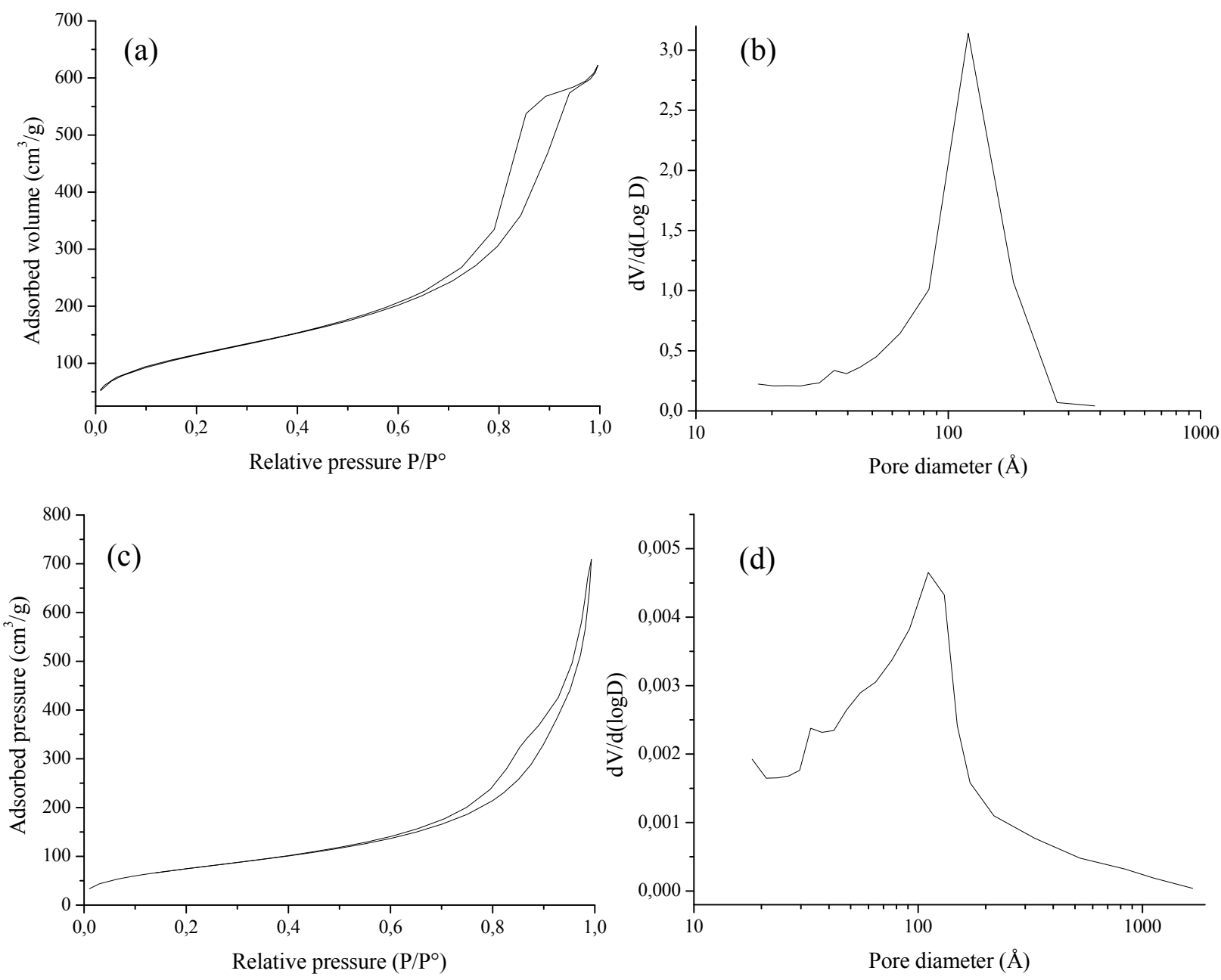

Fig. $4 \mathrm{~N}_{2}$ adsorption-desorption isotherms and pore size distribution of S-2-PhBox-Cu before use $(a, b)$ and after the second run $(c, d)$.

\section{Conclusions}

A series of silica supported heterogeneous $\mathrm{PhBox}-\mathrm{Cu}(\mathrm{II})$ catalysts have been successfully prepared by covalent immobilization on silica supports through carbamate linker. The results obtained in the cyclopropanation of styrene with ethyl diazoacetate have no apparent relationship with the textural properties of the solids. On the contrary, the drop in enantioselectivities with respect to the results in homogeneous phase parallels the behavior observed with a similar ligand indBox, and it seems to be related with the nature of the linker. The presence of coordinating functional groups in the linker, carbamate in this case, seems to be detrimental, probably in connection with a restricted conformational freedom that makes 
difficult the formation of the expected chelate. On the contrary the textural properties of the material do significantly affect the deactivation, mainly due to by-products adsorption.

\section{References}

1. De Vos DE, Vankelecom IFJ, Jacobs PA (Eds.), Chiral Catalysts Immobilization and Recycling, Wiley-VCH, Weinheim, 2000

2. Barbaro P, Liguori F (Eds.), Heterogenized Homogeneous Catalysts for Fine Chemicals Production, Springer, Dordrecht, 2010

3. McMorn P, Hutchings GJ (2004) Chem Soc Rev 33: 108-

4. Heitbaum M, Glorius F, Escher I (2006) Angew Chem Int Ed 45: 4732-4762

5. Fraile JM, García JI, Mayoral JA (2009) Chem Rev 109: 360-417

6. Thomas JM, Raja R (2008) Acc Chem Res 41: 708-720

7. Fraile JM, García JI, Herrerías CI, Mayoral JA, Pires E (2009) Chem Soc Rev 38: 695-706

8. Desimoni G, Faita G, Jorgensen KA (2011) Chem Rev 111: PR284-PR437

9. Li ZH, Zhou ZM, Hao XY, Zhang J, Dong X, Liu YQ (2012) Chirality 24: 1092-1095

10. Wan Y, McMorn P, Hancock FE, Hutchings GJ (2003) Catal Lett 91: 145-148

11. Telalović S, Hanefeld U (2010) Appl Catal A 372: 217-223

12. Feldman RA, Fraile JM (2014) Appl Catal A 485: 67-73

13. Fraile JM, Garcia JI, Herrerias CI, Mayoral JA (2005) Chem Commun 4669-4671

14. Clarke RJ, Shannon IJ (2001) Chem Commun 1936-1937

15. Debono N, Djakovitch L, Pinel C (2006) J Organomet Chem 691: 741-747

16. Debono N, Pinel C, Jahjah R, Alaaeddine A, Delichère P, Lefebvre F, Djakovitch L (2008) J Mol Catal A 287: 142-150

17. Silva AR, Albuquerque H, Borges S, Siegel R, Mafra L, Carvalho AP, Pires J (2012) Micro Meso Mater 158: 26-38

18 Silva AR, Carneiro L, Carvalho AP, Pires J (2013) Catal Sci Technol 3: 2415-2424

19. Lancaster T M, Lee SS, Ying JY (2005) Chem Commun 3577-3579

20. Lee SS, Hadinoto S, Ying JY (2006) Adv Synth Catal 348: 1248-1254

21. Lee SS, Ying JY (2006) J Mol Catal A 256: 219-224

22. Burguete MI, Fraile JM, García JI, García-Verdugo E, Herrerías CI, Luis SV, Mayoral JA (2001) J Org Chem 66: 8893-8901 
23. Corma A, García H, Moussaif A, Sabater MJ, Zniber R, Redouane A (2002) Chem Commun $1058-1059$

24. Park JK, Kim SW, Hyeonb T, Kim BM (2001) Tetrahedron: Asymmetry 12: 2931-2935

25. Lee A, Kim W, Lee J, Hyeon T, Moon Kim B (2004) Tetrahedron: Asymmetry 15: 25952598

26. Rechavi D, Lemaire M (2001) Org Lett 3: 2493-2496

27. Rechavi D, Lemaire M (2002) J Mol Catal A 182-183: 239-247

28. Tada M, Tanaka S, Iwasawa Y (2005) Chem Lett 34: 1362-1363

29. Lee JM, Kim J, Shin JY, Yeom CE, Lee JE, Hyeon T, Kim BM (2010) Tetrahedron: Asymmetry 21: 285-291

30. Fakhfakh F, Baraket L, Ghorbel A, Fraile JM, Herrerías CI, Mayoral JA (2010) J Mol Catal A 329: $21-26$

31. Aggarwal VK, Bell L, Coogan MP, Jubault P (1998) J Chem Soc Perkin Trans $12037-$ 2042

32. Brunauer S, Emmett P H, Teller E (1938) J. Am. Chem. Soc. 60:309-19

33. Barrett ED, Joyner LG, Halenda PP (1951) J. Am. Chem. Soc. 73:373-380

34. Fraile JM, García JI, Mayoral JA, Tarnai T, Harmer MA (1999) J Catal 186: 214-221

35. Fakhfakh F, Baraket L, Fraile JM, Mayoral JA, Ghorbel A (2010) Ann Chim Sci Mat 35: $151-168$

36. Fraile JM, Garcia JI, Gissibl A, Mayoral JA, Pires E, Reiser O, Roldan M, Villalba I, (2007) Chem Eur J 13: 8830-8839

37. Fraile JM, García JI, Jiménez-Osés G, Mayoral JA, Roldán M (2008) Organometallics 27: $2246-2251$

38. Cornejo A, Fraile JM, García JI, Gil MJ, Herrerías CI, Legarreta G, Martínez-Merino V, Mayoral JA (2003) J Mol Catal A 196:101-108

39. García JI, Jiménez-Osés G, López-Sánchez B, Mayoral JA, Vélez A (2010) Dalton Trans 39:2098-2107

40. Albuquerque H, Carneiro L, Carvalho AP, Pires J, Silva AR (2014) Polyhedron 79: 315323

41. Condon JB « Surface Area and Porosity Determination by Physisorption : measurement and theory » Elsevier (2006) first edition.

42. IUPAC Recommendations (1994) Pure Appl Chem 66:1739- 1758. 
43. Fraile JM, García JI, Mayoral JA, Tarnai T (1998) Tetrahedron: Asymmetry 9: 3997-4008 